\title{
ATIVIDADE ANTIBACTERIANA DE Brassica oleracea var. capitata EM MODELOS EXPERIMENTAIS IN VITRO
}

\author{
Thaís Viana Fialho Martins ${ }^{1}$; Patrícia Saraiva Vilas Boas de Almeida ${ }^{1}$; Leandro Licursi de Oliveira ${ }^{2}$; \\ Marilane de Oliveira Fani Amaro ${ }^{2}$; Valéria Dal Prá3; Marcio Mazutti ${ }^{3}$; \\ Marcelo Barcellos da Rosa ${ }^{3}$; Camilo Amaro de Carvalho ${ }^{1^{*}}$ \\ ${ }^{1}$ Departamento de Farmácia - FITOFÁRMACOS, União de Ensino Superior de Viçosa-UNIVIÇOSA, Av. Maria de Paula \\ Santana 3815, Bairro Silvestre, 36570-000, Viçosa-MG, Brasil \\ (tata fialho@yahoo.com.br, pvilasboas@yahoo.com.br, camiloamaro@yahoo.com.br); \\ ${ }^{2}$ Departamento de Biologia Geral, Universidade Federal de Viçosa-UFV, Av.P.H. Rolfs, s/n, Campus Universitário, \\ 36570-000, Viçosa-MG, Brasil. \\ (leandro.licursi@ufv.br, marilaneamaro@yahoo.com.br); \\ ${ }^{3}$ Programa de Pós-graduação em Ciências Farmacêuticas (PPGCF/UFSM), Av. Roraima 1000, Camobi, 97105-900, Santa \\ Maria-RS, Brasil. \\ (vdpdalpra@gmail.com, marciomazutti@gmail.com, marcelobdarosa@gmail.com ).
}

Autor para correspondência: camiloamaro@yahoo.com.br

\section{RESUMO}

A capacidade dos microrganismos, em especial, das bactérias se tornarem resistentes, tem sido amplamente abordada em diversas publicações, e as plantas são uma das fontes para busca de novos medicamentos, que a cada dia vem se tornando mais necessário. Este trabalho, teve por objetivo avaliar diversas formas de preparação de extratos de Brassica oleracea var. capitata e testá-las frentes a cepa de Staphylococcus aureus utilizando ensaio em meio sólido por difusão em ágar, e em meio líquido em placa de ELISA. Os testes revelaram que extratos obtidos por decocção e extração em solvente hidroalcoólico ácido possuem maior apelo para a busca de novos fármacos com atividade frente a $S$. aureus, sendo que deste último as frações obtidas por partição líquido-líquido referentes aos solventes acetato de etila, diclorometano e a fração hidroalcoólica remanescente apresentaram mais eficientes. Já para o meio sólido, verificou-se uma ausência de atividade antibacteriana do extrato hidroalcóolico. Entretanto, uma considerável atividade antibacteriana foi evidenciada nos mesmos extratos quando analisados em meio líquido. Os extratos com concentrações etanólica de 50 e $70 \%$ revelaram melhores resultados quando avaliados por $8 \mathrm{~h}$ de incubação. Resultados diferentes foram observados quando o período foi dobrado, onde as concentrações mais expressivas passaram a ser as de 70 e $80 \%$. Os resultados demonstram que a espécie é uma potencial fonte de agentes antibacterianos. Entretanto, a escolha do solvente, o método de extração e o meio de crescimento bacteriano devem ser considerados. Os dados aqui evidenciados motiva posteriores estudos para o isolamento e identificação dos princípios ativos responsáveis pela atividade antibacteriana que podem ser usadas na indústria farmacêutica, visto o grande número de resistência às drogas antibacterianas já existentes.

Palavras-chave: Agentes Antibacterianos, Plantas medicinais, medicina tradicional, Fitoterapia, Brassica. 


\section{ABSTRACT}

The ability of microorganisms, especially bacteria become resistant, has been widely discussed in various publications, and plants are one source to search for new drugs that each day has become more necessary. This work aimed to evaluate different ways of preparing extracts of Brassica oleracea var. capitata and test them fronts strain of Staphylococcus aureus using the test on solid medium by diffusion in agar and in liquid medium in the ELISA plate. Tests revealed that extracts obtained by solvent extraction and decoction hydroalcoholic acid have greater appeal to the search for new drugs with activity against $S$. aureus, and the latter fractions obtained by liquidliquid partition relating to solvents ethyl acetate, dichloromethane and hydroalcoholic remaining fraction showed more efficient. As for the solid medium, there was a lack of antibacterial activity of hydroalcoholic extract. However, a strong antibacterial activity was observed when analyzed in the same extracts in liquid medium. Ethanolic extracts with concentrations of 50 and $70 \%$ showed better results when evaluated for $8 \mathrm{~h}$ of incubation. Different results were observed when the period was bent where the concentrations became more expressive of the 70 and $80 \%$. The results demonstrate that the species is a potential source of antibacterial agents. However, the choice of solvent, the extraction method and the bacterial growth medium should be considered. The data shown here motivates further studies for the isolation and identification of the active principles responsible for the antibacterial activity that can be used in the pharmaceutical industry, because of the large number of resistance to existing antibacterial drugs.

Key-words: Anti-Bacterial Agents, Plants Medicinal, Medicine Traditional, Phytotherapy, Brassica.

\section{INTRODUÇÃO}

As plantas medicinais representam fator de grande importância para a manutenção das condições de saúde da população mundial ${ }^{(1,2)}$. As espécies vegetais têm sido utilizadas por longos anos sendo seus extratos e preparações administradas na tentativa de tratar doenças, bem como aliviar sintomas ${ }^{(3)}$. Estes procedimentos têm sido mantidos por gerações devido ao baixo custo das plantas medicinais e baixos efeitos colaterais ${ }^{(4)}$.

Esta fonte se torna mais valiosa quando considerado que as espécies vegetais são ricas em uma ampla variedade de metabólitos secundários, tais como os taninos, terpenos, alcalóides e flavonóides, que têm sido estudados por seu potencial antimicrobiano in vitro ${ }^{(6)}$.

Porém, o desenvolvimento de resistência aos antimicrobianos por diversos patógenos vem aumentando a cada dia, tornando-se de grande importância à pesquisa de novos agentes para o combate de infecções.

A Brassica oleracea var. capitata é uma hortaliça anual herbácea da família Brassicacea e tem como região de origem a Costa Norte Mediterrânea, Ásia Menor e Costa Ocidental Européia. A família Brassicacea compreende aproximadamente 350 gêneros e 3000 espécies, distribuídas em todo o mundo, mas principalmente em regiões de clima temperado ${ }^{(9)}$. Constitui a família botânica que abrange o maior número de culturas oleráceas, ocupando lugar proeminente na olericultura do centro-sul do Brasil ${ }^{(11)}$.

No Brasil, Brassica oleracea var. capitata vem sendo utilizada como produto cicatrizante ressaltando o seu uso em casos de diabetes, visto que o quadro clínico de dificuldade de 
cicatrização decorrente da doença é comprovado. Vários estudos têm sido realizados, como de toxicidade e análise histológica, microbiológicos, bioensaios comparativos com outros produtos cicatrizantes, com a finalidade de comprovação científica dos efeitos fitoterápicos da Brassica oleracea var. capitata ${ }^{(12,13)}$.

A atividade antiulcerogenica de Brassica oleracea var. capitata, também foi comprovada por Carvalho ${ }^{(17)}$, ao tratar ratos Wistar durante 7 dias com extrato aquoso da espécie.

Dentre os fatores relacionados com o atraso e a dificuldade de cicatrização estão às bactérias $H$. pylori, na mucosa gástrica, e $S$. aureus na epiderme. Baseando-se em todos esses dados o âmbito dessa pesquisa é aprofundar os estudos na busca de possíveis alternativas de tratamento de infecções bacterianas através do estudo da atividade antibacteriana de diferentes extratos de Brassica oleracea var. capitata frente a cepa de Staphylococcus aureus. O experimento também teve por objetivo comparar a influencia do modo de preparo dos extratos.

\section{MATERIAL E MÉTODOS}

\section{Material botânico}

As folhas de Brassica oleracea variedade capitata (Repolho), no estágio fenológico IX, conforme descrição de Carvalho et al. ${ }^{(12)}$, foram obtidas comercialmente em Viçosa $\left(20^{\circ} 45^{\prime} 14^{\prime \prime}\right.$ de latitude S, e $42^{\circ} 52^{\prime} 54^{\prime \prime}$ de longitude W), Minas Gerais, Brasil. O estágio fenológico foi escolhido de modo que representasse as condições conforme o uso popular.

As folhas de repolho foram lavadas em água corrente, trituradas e divididas em duas amostras: uma destinada à retirada total da água para posterior preparo dos extratos ${ }^{(18)}$; e uma segunda amostra da planta fresca/crua foi triturada em grau de porcelana e destinada a preparar extratos com a espécie na forma in natura ${ }^{(19)}$.

Todos os solventes e modos de extração foram utilizados para verificação de possível interferência sobre o crescimento bacteriano de $S$. aureus.

\section{Preparo dos Extratos}

\section{Extratos da espécie preparados após secagem}

Folhas de $B$. oleracea var. capitata foram destinadas à desidratação em estufa de ar circulante $(50 \pm 5 \mathrm{O})$ por 5 dias e trituradas em gral de porcelana para posterior preparo dos extratos, conforme descrição por Simões et al. ${ }^{(18)}$. Os extratos foram divididos em: etanólico, hidroalcoólico (0 a 100\%) e hidroalcoólico ácido pH 4.

\section{Extrato Etanólico}

Uma amostra de $10 \mathrm{~g}$ da planta seca foi adicionada a $40 \mathrm{~mL}$ de álcool etílico (P.A.) absoluto $(25 \%-\mathrm{m} / \mathrm{v})$, e macerado por $24 \mathrm{~h}$ sob agitação constante à temperatura ambiente $(28 \% \mathrm{C})$. O extrato foi filtrado a vácuo, recolhido e levado a evaporador rotatório (35으) com baixa pressão para total retirada total do solvente. A porção extraída foi ressuspendida em $2 \mathrm{~mL}$ de água destilada. Desta foi retirada uma alíquota de $10 \mu \mathrm{L}$, para a avaliação da atividade antimicrobiana frente a $S$. aureus. 


\section{Extratos Hidroalcoólicos}

Foram feitas soluções hidroalcoólicas variando a concentração etanólica de 0 a $100 \%$ (v/v) com intervalos de $10 \%$, utilizando-se álcool etílico absoluto e água destilada. A extração ocorreu durante $24 \mathrm{~h}$ e sob agitação constante à temperatura ambiente $\left(28^{\circ} \mathrm{C}\right)$. Os extratos foram filtrados à vácuo.

A total remoção do solvente dos extratos foi realizada em estufa a $55^{\circ} \mathrm{C}$ por $24 \mathrm{~h}$. Uma alíquota de $10 \mu \mathrm{L}$ de cada extrato foi utilizada para a avaliação da atividade antimicrobiana frente a S. aureus.

\section{Extrato Hidroalcoólico Ácido}

Extratos de Brassica oleracea var. capitata a $25 \%(\mathrm{~m} / \mathrm{v})$ de planta seca, foram preparados com uma solução de ácido acético:etanol (4:1) em pH 4. A extração ocorreu durante 24 h e sob agitação constante à temperatura ambiente $(28$ ㄷ $)$. Os extratos foram filtrados à vácuo.

A total remoção do solvente dos extratos foi realizada em estufa a 55 으 por $24 \mathrm{~h}$ e ressuspendido em água. Desta, foi retirada uma alíquota de $10 \mu \mathrm{L}$ para a avaliação da atividade antimicrobiana frente a $S$. aureus.

\section{Extrato Hidroalcoólico Ácido Submetido a Processo de Partição Líquido-Líquido}

O procedimento de partição líquido-líquido foi realizado conforme o esquema (Figura 1).

A uma amostra de $500 \mu \mathrm{L}$ do extrato hidroalcoólico ácido, previamente descrito, foram adicionados $300 \mu \mathrm{L}$ de diclorometano (P.A.) e agitou-se por 30 segundos. Após a separação de fases, a alíquota correspondente ao solvente foi retirada (Fase I).

Sobre a fração restante (Fase II), verteu-se $300 \mu \mathrm{L}$ de acetato de etila, agitou-se por 30 segundos e retirou-se a fração correspondente ao solvente (Fase III). À fase restante (Fase IV) foram adicionados $300 \mu \mathrm{L}$ de hexano. Em seguida, as frações formadas (Fase $V$ e VI) foram reservadas.

A total remoção do solvente dos extratos foi realizada em estufa a 55 으 por $24 \mathrm{~h}$ e ressuspendido em água. De cada amostra (Fases I, III, V e VI) foi retirada uma alíquota de $10 \mu \mathrm{L}$ para a avaliação da atividade antimicrobiana frente a $S$. aureus.

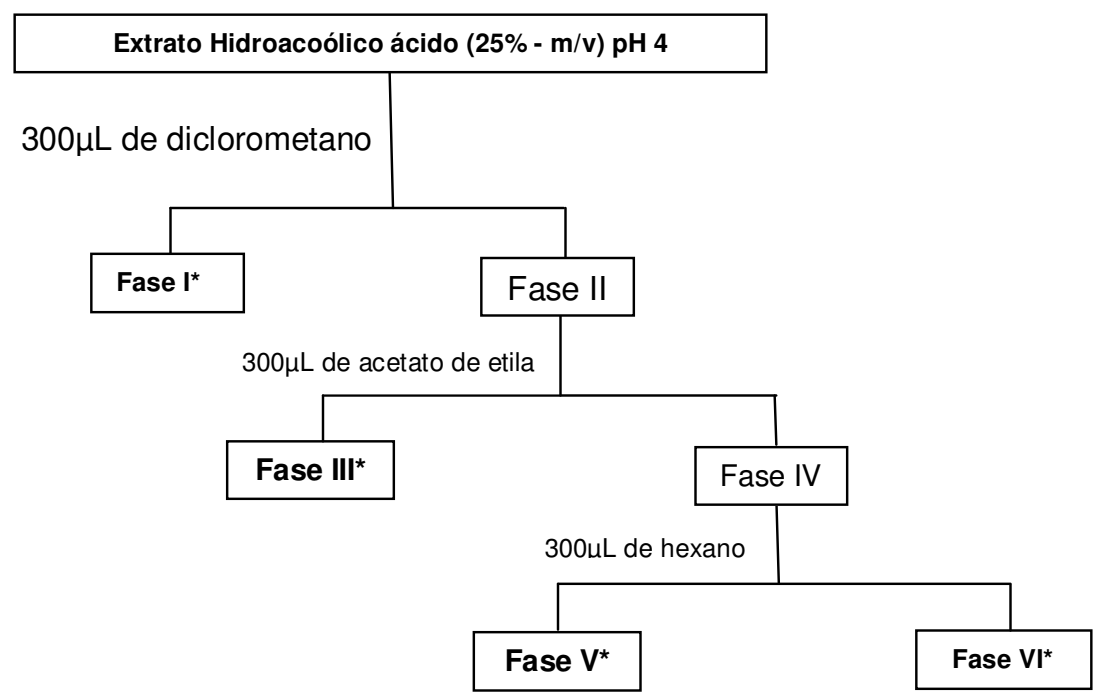

FIGURA 1. Esquema de procedimento de extração por partição líquido-líquido. (*) Fases utilizadas para a avaliação. 


\section{Extratos frescos/cru da espécie}

Com a finalidade de reproduzir as formas convencionais, utilizada pela população conforme descrição ${ }^{(19)}$, uma segunda amostra da planta fresca/crua foi triturada em grau de porcelana e destinada a preparar extratos com a espécie na forma in natura. Estes, foram preparados na forma de extratos por decocção, infuso e turbilhonamento. De cada um dos extratos descritos abaixo, uma alíquota de $10 \mu \mathrm{L}$ foi retirada para a avaliada da atividade antimicrobiana frente a $S$. aureus.

\section{Extração por Decoç̧ão}

Um extrato aquoso de folhas frescas de Brassica oleracea var. capitata foi preparado à $25 \%$ $(\mathrm{m} / \mathrm{v})$. Em seguida o extrato foi aquecido à fervura por 5 minutos. Foi filtrado à temperatura ambiente para posterior avaliação da atividade antibacteriana frente a $S$. aureus.

\section{Extração por Infusão}

Adicionou-se partes de planta fresca e triturada em de água fervendo $(25 \%-\mathrm{m} / \mathrm{v})$, mantendo-o em repouso por 5 minutos para extração. Logo em seguida o extrato foi resfriado em banho de água e em seguida filtrado à temperatura ambiente para posterior avaliação da atividade antibacteriana frente a $S$. aureus.

\section{Extração por Turbolização}

Uma alíquota da espécie fresca foi triturada em grau de porcelana contendo àgua como solvente $(25 \%-\mathrm{m} / \mathrm{v})$. 0 extrato foi prensado por 5 minutos, afim de permitir a liberação máxima dos fitoconstituintes. Posteriormente foi avaliado a atividade antibacteriana frente a $S$. aureus.

\section{Avaliação da Atividade Antimicrobiana}

\section{Bactérias}

A bactéria Staphylococcus aureus ATCC 33591 foi fornecida pelo laboratório de Biologia Molecular - DBB/UFV, que mantém cultura deste micro-organismo como rotina. Essas bactérias foram congeladas a $-20^{\circ} \mathrm{C}$ em meio de cultura contendo glicerol. Para isso, as culturas foram inoculadas em tubos contendo LB (Luria-Bertani) na forma de caldo e incubadas a $37^{\circ} \mathrm{C}$ durante 24h. Posteriormente, alíquotas de $0,5 \mathrm{~mL}$ foram transferidas para tubos de microcentrífuga adicionados de $0,5 \mathrm{~mL}$ de glicerol $87 \%$ estéril.

A cultura foi descongelada, estriada por esgotamento em placa contendo meio Mueller Hinton e em seguida encubado em estufa a $37^{\circ} \mathrm{C}$ por $24 \mathrm{~h}$, para ser posteriormente utilizada na avaliação da atividade antimicrobiana por ensaio de difusão em ágar.

Já para o teste antimicrobiano em meio LB líquido, a cultura foi descongelada, e desta foi retirada uma alíquota de $10 \mu \mathrm{L}$, que foi ressuspendida em $5 \mathrm{~mL}$ do próprio meio utilizado para o teste e encubado nas mesmas condições descritas anteriormente.Todas as colônias foram periodicamente renovadas. 


\section{Ensaio em Meio Sólido por Difusão em Agar}

Colônias de $S$. aureus presente nas placas estriadas, foram transferidas para salina $0,9 \%$ chegando a concentração bacteriana de $10^{8}$ UFC. $\mathrm{mL}^{-1}$ (0,5 na escala de McFarland). Alíquotas de $0,5 \mathrm{~mL}$ dessa suspensão foram adicionadas a $12,5 \mathrm{~mL}$ de meio Muller Hinton fundido $\left( \pm 45^{\circ} \mathrm{C}\right)$. A mistura foi vertida em placa de Petri. Foram feitos poços de $3 \mathrm{~mm}$ no meio solidificado, onde foram adicionados alíquotas de $10 \mu \mathrm{L}$ das amostras testadas. O controle para ausência de crescimento foi feito com a gentamicina $4 \mathrm{mg} \cdot \mathrm{mL}^{-1}$ e para o crescimento pleno, foi utilizado a salina $0,9 \%$ estéril, adicionados as placas testes. A placa foi incubada a $37^{\circ} \mathrm{C}$ por $24 \mathrm{~h}$. A atividade antimicrobiana foi avaliada pela observação da inibição do crescimento da bactéria através de halos formados na placa.

\section{Ensaio em Meio Líquido em Placa de ELISA}

A atividade antimicrobiana foi avaliada medindo-se a densidade óptica dos meios, em um comprimento de onda de $600 \mathrm{~nm}$. Inicialmente, alíquotas de $200 \mu \mathrm{L}$ dos extratos preparados variando a concentração hidroalcoólica foram separadas e levadas à estufa a 55ㄷ para evaporação do solvente restando-se apenas pellets para garantia de que não houvesse influência do álcool sobre o experimento. Após a evaporação os extratos, permaneceram sob luz UV em capela de fluxo laminar por período de $1 \mathrm{~h}$ para a esterilização da amostra. Estes pellets foram ressuspendidos em $200 \mu \mathrm{L}$ de meio LB.

Para o crescimento pleno das bactérias, alíquotas de $10 \mu \mathrm{L}$ de meio LB previamente preparado contendo as bactérias eram adicionadas a um novo meio e já no controle da ausência de crescimento bacteriano, foi utilizado $10 \mu \mathrm{L}$ de gentamicina $4 \mathrm{mg} \cdot \mathrm{mL}^{-1}$, adicionados ao poço que continha também $50 \mu \mathrm{L}$ meio com bactérias. Como branco foram utilizados alíquotas de meio LB puro. Os testes foram realizados em triplicata utilizando-se placa de ELISA como descrito na Tabela1.

O experimento foi realizado em capela de fluxo laminar garantindo a não contaminação da placa. A placa foi incubada a $37^{\circ} \mathrm{C}$ por $8 \mathrm{~h}$ e foi realizada a leitura da absorbância em leitor de placa de ELISA a 600nm (ELISA VERSA MAX - Microplate Eader ${ }^{\circ}$ ).

Para avaliar o efeito do extrato sobre a influência do tempo de incubação sobre o crescimento bacteriano, o experimento foi realizado em um período de 8 e 16 horas de incubação. 
TABELA 1. Preparo da placa para avaliação da inibição do crescimento bacteriano em meio líquido dos extratos de Brassica oleracea var. capitata.

\begin{tabular}{|c|c|c|c|c|}
\hline Testes & LB & Meio e S. aureus & $\begin{array}{c}\text { Gentamicina } \\
4 \mathrm{mg} \cdot \mathrm{mL}^{-1}\end{array}$ & Extratos \\
\hline $\mathrm{CO}$ & $200 \mu l$ & - & - & - \\
\hline $\mathrm{C}-$ & $150 \mu l$ & $50 \mu \mathrm{l}$ & - & - \\
\hline $\mathrm{C}_{+}$ & $140 \mu \mathrm{l}$ & $50 \mu \mathrm{l}$ & $10 \mu \mathrm{l}$ & - \\
\hline $0 \%$ & $100 \mu \mathrm{l}$ & $50 \mu l$ & - & $50 \mu \mathrm{l}$ \\
\hline $10 \%$ & $100 \mu \mathrm{l}$ & $50 \mu l$ & - & $50 \mu \mathrm{l}$ \\
\hline $20 \%$ & $100 \mu \mathrm{l}$ & $50 \mu \mathrm{l}$ & - & $50 \mu l$ \\
\hline $30 \%$ & $100 \mu \mathrm{l}$ & $50 \mu \mathrm{l}$ & - & $50 \mu l$ \\
\hline $40 \%$ & $100 \mu \mathrm{l}$ & $50 \mu \mathrm{l}$ & - & $50 \mu l$ \\
\hline $50 \%$ & $100 \mu \mathrm{l}$ & $50 \mu l$ & - & $50 \mu \mathrm{l}$ \\
\hline $60 \%$ & $100 \mu \mathrm{l}$ & $50 \mu \mathrm{l}$ & - & $50 \mu l$ \\
\hline $70 \%$ & $100 \mu \mathrm{l}$ & $50 \mu \mathrm{l}$ & - & $50 \mu l$ \\
\hline $80 \%$ & $100 \mu \mathrm{l}$ & $50 \mu \mathrm{l}$ & - & $50 \mu \mathrm{l}$ \\
\hline $90 \%$ & $100 \mu \mathrm{l}$ & $50 \mu \mathrm{l}$ & - & $50 \mu \mathrm{l}$ \\
\hline $100 \%$ & $100 \mu \mathrm{l}$ & $50 \mu \mathrm{l}$ & - & $50 \mu \mathrm{l}$ \\
\hline
\end{tabular}

\section{Análise Estatística}

Para interpretação dos resultados da atividade antibacteriana dos diversos extratos em concentrações hidroalcoólicas diferentes, foi realizada analise de variância (ANOVA), seguido do teste de Tukey ao nível de $5 \%$ de probabilidade.

\section{RESULTADOS E DISCUSSÃO}

Ao realizar os testes de atividade antibacteriana frente $S$. aureus, os extratos obtidos a partir da utilização da planta fresca por turbolização e infusão, não apresentaram halos de inibição do crescimento. Já o extrato obtido através de decocção exibiu halos de $9 \mathrm{~mm}$ referentes à inibição bacteriana (Figura 2). Corroborando com estes dados Gnoatto e colaboradores ${ }^{(20)}$ ao realizar testes comparando os métodos de extração em Soxhlet e decocção, para a planta Ilex paraguariensis (Erva mate), observaram a superioridade da decocção em relação à extração por Soxhlet.

Os processos de extração dependem, em grande parte, da temperatura uma vez que o aumento desta, provoca um aumento da solubilidade de qualquer substância ${ }^{(18)}$. Entretanto, o calor nem sempre pode ser empregado já que muitas substâncias são instáveis às altas temperaturas.

Considerando os estudos realizados por Gnoatto et al. ${ }^{(20)}$ e os resultados obtidos nesta pesquisa para comparação entre os três métodos extrativos (Figura 2), pode-se dizer que a temperatura é um fator de suma importância para o processo de extração. Tal resultado apoia as conclusões de Astill et al. ${ }^{(21)}$, que consideraram a temperatura como o fator que mais contribui para a eficiência da extração dos bioativos de amostras de chás. 
O extrato etanólico bruto $(25 \%-\mathrm{m} / \mathrm{v})$ macerado por $24 \mathrm{~h}$ sob agitação constante à temperatura ambiente $\left(28^{\circ} \mathrm{C}\right)$ não apresentou atividade antibacteriana. Já o extrato hidroalcoólico ácido ( $\mathrm{pH}$ 4) apresentou atividade demonstrada através da formação de um halo de inibição de crescimento bacteriano de $24 \mathrm{~mm}$ (Figura 2).

O etanol é responsável pela extração de compostos como agliconas, ceras, sapogeninas, iridóides e sesquiterpenos e a água, por extrair substâncias hidrofílicas como aminoácidos, açúcares, alcalóides, saponinas, heterosídeos flavonoídicos e mucilagens ${ }^{(18)}$. Portanto a não obtenção de um halo de inibição bacteriana do extrato etanólico bruto de Brassica oleracea var. capitata pode ser justificada uma vez que grande parte dos compostos presentes nesta planta não são extraídos por etanol absoluto.

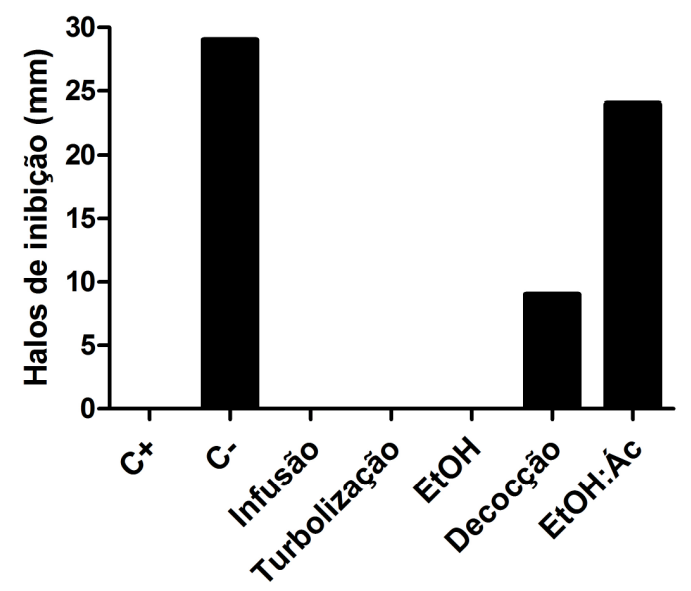

FIGURA 2. Atividade antibacteriana de extratos de Brassica oleracea var. capitata frente a S. aureus. EtOH - Extrato etanólico; EtOH:Ác. - Extrato hidroalcoólico ácido $(\mathrm{pH} 4)$; $(\mathrm{C}+)$ - Controle positivo (gentamicina $\left.4 \mathrm{mg} \cdot \mathrm{mL}^{-1}\right)$; (C-) -

Controle negativo (solventes).

A acidificação utilizada na extração conduzem a maiores rendimentos de metabólitos extraídos, o que está provavelmente relacionado com a descomplexação e à protonação das moléculas em meio ácido, tornando-os muito mais solúveis em água. Além disso, o uso do solvente em $\mathrm{pH}$ ácido é capaz de tornar as moléculas alcalinas mais solúveis no meio extrativo(20), o que poderia justificar a atividade observada.

O uso do solvente hidroalcoólico apresenta uma maior eficiência, melhorando em princípio a solubilidade das substâncias semi-polares como é o caso dos alcaloides e flavonoides ${ }^{(22)}$, entre outros metabólitos secundários que poderiam estar relacionados com atividade antibacteriana. Sendo fundamental no processo de extração, pois é responsável por selecionar e determinar as substâncias a serem extraídas, de acordo com suas características químicas e de polaridade ${ }^{(23)}$. Estes estudos justificam a utilização de uma solução hidroalcoólica acidificada para que haja uma maior eficiência no processo de extração de compostos bioativos de plantas, o que fica demonstrado através dos resultados obtidos. 

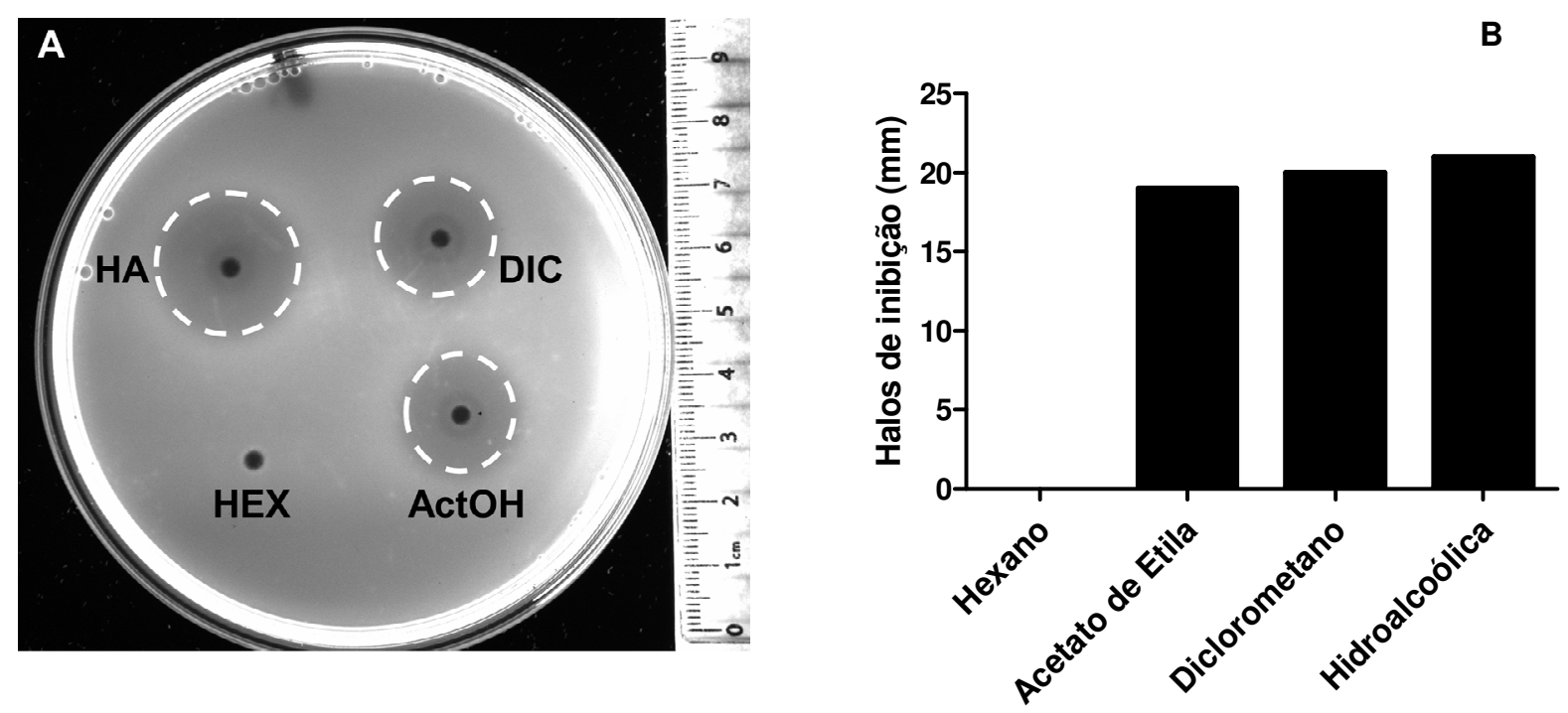

FIGURA 3. Atividade antibacteriana de frações do extrato de Brassica oleracea var. capitata. A - Halos de inibição em meio sólido; B - Frações: DIC - diclorometano; HEX - hexano; ActOH - acetato de etila e HA - Hidroalcoólica remanescente utilizados em partição líquido-líquido feita a partir do extrato hidroalcoólico ácido (pH 4).

Posteriormente a uma extração hidroalcoólica, o extrato deve ser submetido a um processo de partição líquido-líquido, com solventes de polaridades crescentes, como hexano, diclorometano, acetato de etila e butanol, visando uma semi-purificação das substâncias através de suas polaridades. No sentido de localizar os princípios ativos, todos os extratos semi-puros devem ser testados e aquele que apresentar efeito biológico de interesse, poderá ser submetido aos procedimentos cromatográficos para o isolamento e a purificação dos $\operatorname{compostos}^{(24)}$.

Para avaliação da influência da polaridade dos fitoconstituintes do extrato de $B$. oleracea var. capitata, o extrato hidroalcoólico ácido foi submetido à partição Líquido-Líquido onde obtevese halos nas fases referentes ao acetato de etila $(19 \mathrm{~mm})$, diclorometano $(20 \mathrm{~mm})$ e na fração hidroalcoólica remanescente $(21 \mathrm{~mm})$ (Figura 3 ).

Os solventes utilizados nesta pesquisa são capazes de extrair compostos antracênicos (diclorometanos), cumarinas e flavonóides (acetato de etila), furanocumarinas (hexano) e taninos e alcalóides (misturas hidroalcoólicas) ${ }^{(18)}$. Apesar de não ter sido confirmado a presença dos metabólitos em cada fração, em estudos realizados por Carvalho et al. ${ }^{(12)}$ foi verificada a presença destes metabólitos secundários em extratos de Brassica oleracea var. capitata .

Nos testes realizados com extratos hidroalcoólicos a $10 \%(\mathrm{~m} / \mathrm{v})$ com concentrações etanólicas crescentes 0 a 100\% (v/v) por difusão em meio sólido, não foram observados halos em nenhuma das concentrações etanólicas analisadas. Já em meio LB líquido estes extratos proporcionou resultados promissores em diferentes concentrações alcoólicas (Tabela 2). A inibição significativa do crescimento foi verificada nas concentrações de 40 a $80 \%$, sendo o crescimento inibido em mais de $50 \%$, nos extratos de concentrações hidroalcoólicas de 50 e $70 \%$ das amostras incubadas por um período de 8 horas (Figura 4A). 

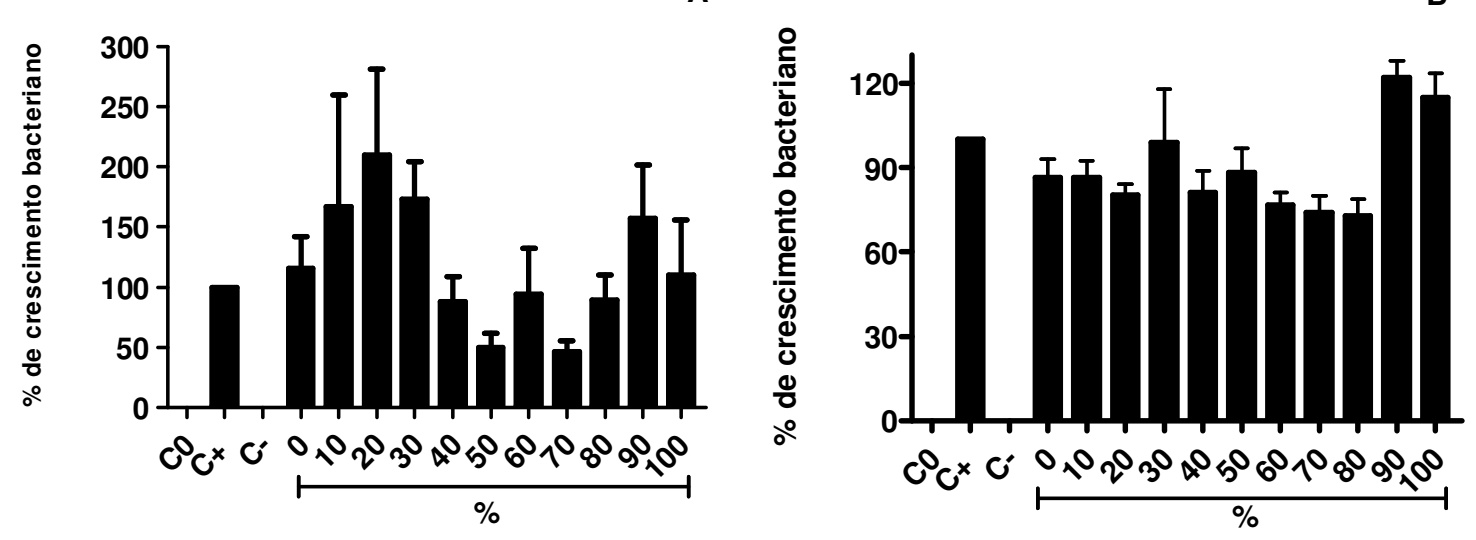

FIGURA 4. Influência do tempo em relação à atividade antibacteriana de extratos hidroalcoólicos (0 a 100\% - v/v) de Brassica oleracea var. capitata. A e B - Crescimento bacteriano avaliado após 8 h e $16 \mathrm{~h}$ de incubação, respectivamente. CO - Somente LB (Luria-Bertani); (C+) - Controle positivo; (C-) - Controle negativo (gentamicina $4 \mathrm{mg}^{\mathrm{mL}} \mathrm{mL}^{-1}$ ).

O tempo de permanência da placa na estufa foi avaliado, permanecendo uma segunda amostra incubada por um período de 16 horas nas mesmas condições (Figura 4B, Tabela 2). A escolha dos tempos levou em consideração a utilização convencional dos antibacterianos comerciais. Entretanto foram desconsiderações os aspectos farmacocinéticos de distribuição e metabolismo, uma vez que o experimento foi conduzido in vitro.

A avaliação permitiu verificar uma atividade bacteriostática em nove das onze amostras testadas, nas concentrações de 0 a $80 \%(\mathrm{v} / \mathrm{v})$ frente ao crescimento bacteriano visto que não houve ausência de crescimento o que caracterizaria atividade bactericida. Os resultados mais expressivos foram observados nas concentrações hidroalcoólica de 70 e $80 \%$, com uma inibição de 30 a $40 \%$ do crescimento bacteriano (Figura 4B).

Os resultados permitem inferir que há um aumento considerável na inibição do crescimento bacteriano da maioria dos extratos o que mostra que o tempo de incubação para a ação dos extratos é um fator que pode interferir significativamente em sua ação.

A avaliação da atividade frente a outras espécies de microrganismos contribuirá para uma melhor definição do perfil de atividade antimicrobiana Brassica oleracea var. capitata e de eventuais diferenças entre extratos obtidos a partir de diferentes formas de extração. 
TABELA 2: Atividade antibacteriana de Brassica oleracea var. capitata frente S. aureus incubadas em meio líquido por $8 \mathrm{~h}$ e $16 \mathrm{~h}$ à $37^{\circ} \mathrm{C}$.

\begin{tabular}{|c|c|c|c|c|c|c|c|c|c|c|}
\hline \multirow[b]{2}{*}{ Conc. } & \multicolumn{5}{|c|}{8 horas de incubação } & \multicolumn{5}{|c|}{16 horas de incubação } \\
\hline & \multicolumn{3}{|c|}{ Abs } & \multirow{2}{*}{$\begin{array}{c}\text { Média* } \\
0_{c}\end{array}$} & \multirow{2}{*}{$\begin{array}{c}\text { \% Relativa } \\
0,0\end{array}$} & \multicolumn{3}{|c|}{ Abs } & \multirow{2}{*}{$\begin{array}{c}\text { Média* } \\
0_{D}\end{array}$} & \multirow{2}{*}{$\begin{array}{c}\text { \% Relativa } \\
0\end{array}$} \\
\hline CO & 0 & 0 & 0,0 & & & 0 & 0 & 0 & & \\
\hline C- & 0,29 & 0,27 & 100,0 & $0,23{ }_{A B C}$ & 100,0 & 0,6 & 0,73 & 0,66 & $0,66_{A B}$ & 100 \\
\hline $\mathrm{C}_{+}$ & 0 & 0 & 0,0 & $0_{c}$ & 0,0 & 0 & 0 & 0 & $0_{D}$ & 0 \\
\hline $0 \%$ & 0,35 & 0,18 & 121,7 & $0,28{ }_{A B C}$ & 121,7 & 0,56 & 0,54 & 0,61 & $0,57 \mathrm{BC}$ & 86,4 \\
\hline $10 \%$ & 0,45 & 0,03 & 130,4 & $0,30 \mathrm{AB}$ & 130,4 & 0,57 & 0,55 & 0,59 & $0,57 \mathrm{BC}$ & 86,4 \\
\hline $20 \%$ & 0,50 & 0,29 & 178,3 & $0,41_{A}$ & 178,3 & 0,5 & 0,53 & 0,56 & $0,53 \mathrm{BC}$ & 80,3 \\
\hline $30 \%$ & 0,53 & 0,31 & 165,2 & $0,38 \mathrm{AB}$ & 165,2 & 0,82 & 0,55 & 0,56 & $0,644_{A B C}$ & 97,0 \\
\hline $40 \%$ & 0,33 & 0,13 & 91,3 & $0,21_{A B C}$ & 91,3 & 0,56 & 0,49 & 0,55 & $0,53_{\mathrm{BC}}$ & 80,3 \\
\hline $50 \%$ & 0,11 & 0,09 & 43,5 & $0,10_{\mathrm{BC}}$ & 43,5 & 0,53 & 0,53 & 0,68 & $0,58 \mathrm{BC}$ & 87,9 \\
\hline $60 \%$ & 0,16 & 0,15 & 69,6 & $0,16_{A B C}$ & 69,6 & 0,5 & 0,5 & 0,52 & $0,50_{\mathrm{BC}}$ & 77,3 \\
\hline $70 \%$ & 0,13 & 0,08 & 43,5 & $0,10_{\mathrm{BC}}$ & 43,5 & 0,5 & 0,46 & 0,5 & $0,48 c$ & 74,2 \\
\hline $80 \%$ & 0,21 & 0,17 & 78,3 & $0,18 \mathrm{ABC}$ & 78,3 & 0,46 & 0,45 & 0,53 & $0,48 c$ & 72,7 \\
\hline $90 \%$ & 0,33 & 0,29 & 134,8 & $0,31_{A B}$ & 134,8 & 0,75 & 0,84 & 0,77 & $0,79_{A}$ & 119,7 \\
\hline $100 \%$ & 0,57 & 0,14 & 117,4 & $0,27 \mathrm{ABC}$ & 117,4 & 0,76 & 0,72 & 0,79 & $0,76_{A}$ & 115,2 \\
\hline \multicolumn{4}{|c|}{ Coeficiente de Variação } & & 45,732 & & & & & 11,2 \\
\hline
\end{tabular}

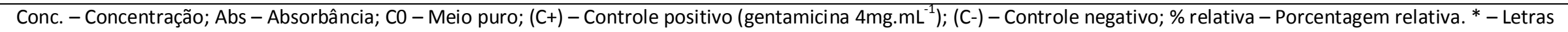
iguais na mesma coluna demonstram que as médias não diferiram pelo teste de Tukey ao nível de $5 \%$ de probabilidade. 


\section{CONCLUSÃO}

A espécie Brassica oleracea var. capitata (Repolho Branco) é uma potencial fonte de agentes antibacterianos. Entretanto, a escolha do solvente, o método de extração e o meio de crescimento bacteriano devem ser considerados, uma vez que neste estudo foi verificada uma grande variação entre às variáveis avaliadas.

Os dados aqui evidenciados motiva posteriores estudos para o isolamento e identificação dos princípios ativos responsáveis pela atividade antibacteriana que podem ser usadas na indústria farmacêutica, visto o grande número de resistência às drogas antibacterianas já existentes.

\section{REFERÊNCIAS BIBLIOGRÁFICAS}

1. Klein T, Longhini R, Bruschi ML et al. Fitoterápicos: um mercado promissor. Revista Ciência Farmacêutica Básica Aplicada, 2009, 30(3):241-248.

2. Barreto F, Sousa E, Campos A et al. Antibacterial Activity of Lantana camara Linn and Lantana montevidensis Brig Extracts from Cariri-Ceará, Brazil. Journal of Young Pharmacists, 2010, 2(1):4244.

3. Höfling JF, Anibal PC, Obando-Pereda GA et al. Antimicrobial potential of some plant extracts against Candida species. Brazilian Journal of Biology, 2010, 70(4):1065-1068.

4. Ponzi EAC, Oliveira TL, Morais IAF et al. Antimicrobial activity of the Momordica charantia L. extract. Revista de Cirurgia e Traumatologia Buco-Maxilo-facial, 2010, 10(1):89-94.

5. Lorenzi H, Matos FJ De A. Plantas medicinais no Brasil/Nativas e exóticas. 1.ed. Nova Odessa, Instituto Plantarum, 2002:512.

6. Jain P, Bansal D, Bhasin P. Antibacterial activity of aqueous plant extracts against Escherichia coli and Bacillus subtilis. Drug Invention Today, 2010, 2(4):220-222.

7. Costa JGM, Rodrigues FFG, Angélico EC et al. Estudo químico-biológico dos óleos essenciais de Hyptis martiusii, Lippia sidoides e Syzigium aromaticum frente a larvas do Aedes aegypti. Revista Brasileira de Farmacognosia, 2005, 15(4):304-309.

8. Oliveira TG, Carvalho CA, Dal'piva GG et al. Chromatographic and spectrophotometric profiles of different phenologic stages of Brassica oleracea var. capitata. Revista Eletrônica de Farmácia, 2007, 4(2):142-152.

9. Monsalve C, Cano A. La Família Brassicaceae em la província de Huaylas, Áncash. Revista Peruana de Biologia, 2003, 10(1):20-32.

10. Fracaro F, Sartori M, Bizzani E et al. Agronomic Behavior of Cabbage Cultivars and Hybrids in the Northeast Region of Rio Grande do Sul, Brasil. Revista de Ciência Rural, 1999, 29(3):465-468.

11. Filgueira FAR. Novo Manual de Olericultura: agrotecnologia moderna na produção e comercialização de hortaliças. 3.ed. Viçosa, UFV, 2000:421.

12. Carvalho CA, Silva MB, Oliveira TG et al. Estudo espectrométrico de diferentes estágios fenológicos da Brassica oleracea var. capitata. Revista Brasileira de Farmacognosia, 2008, 18(2):249-257.

13. Sarandy MM. Avaliação do efeito cicatrizante do extrato de repolho (Brassica oleraceae var. capitata) em ratos Winstar. 2007. 57p. Dissertação para o Programa de Pós Graduação em Biologia Celular e Estrutural, Universidade Federal de Viçosa, Viçosa.

14. Cheney G. Vitamin U therapy of pepticulcer. California Medicine, 1952, 77(4):248-252. 
15. Ranocha P, Mcneil SD, Ziemak MJ et al. The S-methylmethionine cycle in angiosperms: ubiquity, antiquity and activity. The Plant Journal, 2001, 25(5):575-584.

16. Augspurger NR, Scherer CS, Garrow TA et al. Dietary S-Methyl methionine, a component of foods, has choline-sparing activity in chickens. Journal of Nutrition, 2005, 135, 1712-1717.

17. Carvalho CA, Fernandes KM, Matta SLP et al. Evaluation of antiulcerogenic activity of aqueous extract of Brassica oleracea var. capitata (cabbage) on Wistar rat gastric ulceration. Experimental Gastroenterology, 2011, 48(4), p. 276-288

18. Simões CMO, Schenkel EP, Gosmann $\mathrm{G}$ et al. Farmacognosia: da planta ao medicamento. 5.ed. Porto Alegre/Florianópolis, Editora da UFRGS/Editora da UFSC, 2004:1102.

19. Balbach A, Boarim D. As Hortaliças na Medicina Natural. 2.ed. Itaquacetuba, Vida Plena, 1993:280.

20. Gnoatto SCB, Bassani VL, Coelho GC et al. Influência do método de extração nos teores de metilxantinas em erva-mate (Ilex paraguariensis a. st.-Hil., aquifoliaceae). Química Nova, 2007, 30(2), 304-307.

21. Astill C, Birch MR, Dacombe $C$ et al. Factors affecting the caffeine and polyphenol contents of black and Green tea infusions. Journal of Agricultural and Food Chemistry, 2001, 49(11), 5340-5347.

22. Silva IDD, Aragão CFS. Avaliação de parâmetros de extração da Cinchona Vahl por métodos farmacopéicos e não farmacopéicos. Revista Brasileira de Farmacognosia, 2009, 19(3), 776-780.

23. Longhini R, Raksa SM, Oliveira ACP et al. Obtenção de extratos de própolis sob diferentes condições e avaliação de sua atividade antifúngica. Revista Brasileira de Farmacognosia, 2007, 17(3), 388395.

24. Filho VC, Yunes RA. Estratégias para a obtenção de compostos farmacologicamente ativos a partir de plantas medicinais. Conceitos sobre modificação estrutural para otimização da atividade. Quimica Nova, 1998, 21(1), 99-105. 